Dr Stefan Janković,

Miroljub Jovanović, dipl. inž.

\section{Pravci razvoja helikopterskih gasnih turbina}

Gasna turbina, kao turbovratilni gasoturbinski motor (GTM), dovela je do masovne proizvodnje i šroke primene helikoptera $u$ civilne $i$ vojne svrhe.

Pravci daljeg razvoja GTM usmereni su na nova konstruktivna rešenja, na već postojećim modelima GTM, razvoju novih materijala i tehnologija, što je i predmet ovog rada.

\section{Uvod}

Ideju ostvarenja letelice teže od vazduha, sa mogućnošću vertikalnog poletanja, pomoću nosećeg rotora, prvi je prikazao Leonardo da Vinči još 1475. Skica i opis nosećeg rotora, koji se pogoni snagom muskulature čoveka, otkriveni su u Milanskoj biblioteci i publikovani u 19. veku.

Prvi uspešni letovi helikoptera ostvareni su u periodu od 1930. do 1934, sa ruskim eksperimentalnim helikopterom CAGI-1EA sa pogonskom grupom od dva klipna motora ukupne snage od $88 \mathrm{~kW}$.

Početak serijske proizvodnje helikoptera pripada periodu od 1950 . do 1952 , sa klipnim motorima kao pogonskom grupom. Prvi helikopter, opremljen serijski proizvedenom gasnom turbinom ARTUST II, bio je ALUET II. Gasnu turbinu proizvela je TURBOME$\mathrm{KA}$, a jednorotorni helikopter sa rešetkasto-ramovskom konstrukcijom AEROSPASIAL, takođe iz Francuske.

U proteklom periodu, helikopteri su se neprestano usavršavali zajedno sa svojim pogonskim grupama, nalazeći sve veću primenu u vojsci i privredi. $\mathrm{Za}$ izradu helikoptera većih nosivosti zahtevane su nove pogonske grupe, sa malom specifičnom masom i visokom ekonomičnošću. Rešenje je nađeno u gasnoj turbini, kao pogonskoj grupi.
Danas, skoro sve armije sveta poseduju veći ili manji broj helikoptera raznovrsne namene. $\mathrm{Njihov}$ ukupan broj procenjuje se na oko 30.000 .

Približna preraspodela ovog broja helikoptera iznosi:

$\mathrm{SAD}$

- 35\% - vazduhoplovne snage

- 20\% - bivši SSSR, sa bivšim zemljama Varšavskog ugovora, i tak sveta.

Prema sadašnjoj doktrini ratovanja, jedan od važnih kriterijuma za ocenu moći i savremenosti neke armije, predstavlja broj i vrsta helikoptera $u$ njenom naoružanju.

\section{Kratak istorijat razvoja gasnih turbina}

Prvi patent za gasnu turbinu prijavio je S. Barber u Engleskoj 1791. To se dogodilo pre nego što je švedski inženjer Gustav Patrik de Laval patentirao prvu industrijski primenljivu parnu turbinu 1883. godine. Međutim, tehnološko-metalurški razlozi (materijali za rad na visokim temperaturama) i usporen razvoj izučavanja dinamike gasova, onemogućili su brži razvoj gasne turbine. 
Šmu vazdušno-reaktivnog gasoturbinskog motora prvi je predložio i patentirao 1909. ruski inženjer N. Gerasimov. Ova šema imala je tri osnovna sklopa mlaznog propulzora : kompresor, grejnu komoru i turbinu.

Sovjetski istraživač V. I. Bazarov, predložio je 1923. šemu gasoturbinskog motora sa centrifugalnim kompresorom i sagorevanjem pri konstantnom pritisku. Motor V. I. Bazarova je po svojoj šemi sličan savremenim gasoturbinskim motorima tog tipa. Nakon trinaest godina slična šema ponovo je patentirana u Engleskoj (F. Vitl).

Semu turboelisnog gasoturbinskog motora prvi je predložio ruski pukovnik M. Nikolski, 1914.

Treba napomenuti da su naučne osnove radnog ciklusa gasoturbinskih motora bile poznate znatno ranije od njihove praktične primene. Tako je 1929. sovjetski akademik B. Stećkin, u časopisu »Tehnika vazduhoplovstva", objavio poznatu studiju »Teorija vazdušno-reaktivnog motora $u$ kojoj su iznete osnove savremene teorije i proračuna gasoturbinskih motora.

Sovjetski profesor V. V. Uvarov je 1932. započeo rad na originalnoj šemi turboelisnog gasoturbinskog motora, po kojoj je izveden $\mathrm{i}$ ispitan. Motor Uvarova može se smatrati za prvi primenjeni gasoturbinski motor u sovjetskom vazduhoplovstvu. Već 1935 . sovjetski akademik A. M. Ljuljka razvio je turbomlazni gasoturbinski motor.

U Sovjetskom Savezu osnivaju se i mnogobrojni konstruktorski biroi koji su dobili imena po talentovanim konstruktorima i naučnicima koji su radili u njima: A. M. Ljulka, S. K. Tumanski, A. A. Mikulin, V. A. Dobrinin, V. J. Klimov, N. D. Kuznjecov, P. A. Solovjev, A. G. Ivčenko, S. P. Izotov, V. A. Lotarev i drugi. Gasne turbine nose oznake biroa u kojem su projektovane.

U periodu od 1933. pa do drugog svetskog rata pitanjima mlazne propul- zije bave se Moris Rua u Francuskoj, Kampini u Italiji i F. Vitl u Engleskoj. Takođe, u ovim zemljama, kao i u Nemačkoj i SAD, pojavljuju se velike firme $u$ kojima se stvaraju originalne konstrukcije gasoturbinskih motora na visokom tehničkom nivou, čiji se razvoj i usavršavanja i dalje nastavljaju.

Praktično, nagli razvoj gasoturbinskih motora nastaje krajem drugog svetskog rata zbog velikih ulaganja za istraživanja u ratne svrhe, kada su dobijeni materijali otporni na visokim temperaturama i rešeno pitanje stabilnosti strujanja kroz aksijalne kompresore sa više stupnjeva.

Razvoj helikopterskih gasnih turbina nastao je kao rezultat šireg razvoja mlaznih propulzora i zahteva za proširenu upotrebu helikoptera. Primena gasne turbine, kao turbovratilnog gasoturbinskog motora na helikopteru, započeta je sredinom ovog veka. Zahvaljujući značajnim prednostima (niža specifična masa, visoka pouzdanost $u$ radu, jednostavnija eksploatacija, manji poprečni presek, i dr.), gasna turbina je vrlo brzo potisnula upotrebu klipnih motora na helikopteru.

Turbovratilni gasoturbinski motor, osim na helikopteru, primenjuje se $i$ kao pogonska grupa elektroagregata (pokretni i stacionarni), sredstava rečnog, morskog i suvozemnog transporta (brod, čamac, tenk, transporter, lokomotiva tzv. voza velikih brzina - TVG, i dr.), a služi i kao pomoćni agregat za startovanje osnovnog motora na avionu ili helikopteru. Kada ima ulogu startovanja (mehaničko ili pneumatsko) naziva se turbostarter. Turbostarter služi i kao izvor snage za agregate energosistema (generatori, hidro pumpe, i sl.) pri njihovoj proveri na zemlji, ili napajanja u letu u slučaju otkaza pogonske grupe. Ovakva uloga turbostartera obezbeđuje potrebnu upravljivost aviona $u$ slučaju otkaza pogonske grupe. Prvi turbostarteri projektovani su i serijski proizvedeni u Sovjetskom Savezu sredinom ovog veka. Osnovne karakte- 
ristike savremenih turbostartera su: snaga od 50 do $150 \mathrm{~kW}$, specifična masa $\mathrm{C}_{\mathrm{sm}}<0,35 \mathrm{~kg} / \mathrm{kW}$, specifična gabaritna zapremina (male dimenzije zbog smeštaja) od 0,1 do $0,15 \mathrm{dm}^{3} / \mathrm{kW}$ i stepen sabijanja vazduha $\pi_{k}>4$.

\section{Pravci razvoja helikopterskih gasnih turbina}

Potrebna snaga za pogon helikoptera, za jedan određeni režim leta, $u$ najopštijem slučaju iznosi:

$$
P=P_{o}+P_{i}+P_{p}+P_{v}
$$

gde je:

$P_{0}[k W]$ - potrebna snaga za savlađivanje sile otpora aeroprofila lopatica glavnog rotora;

$P_{\mathrm{i}}[\mathrm{kW}]$ - potrebna snaga za savlađivanje sile indukovanog otpora;

$P_{p}[k W]$ - potrebna snaga za savlađivanje parazitnih otpora trupa, repnog rotora, i dr.;
$\mathrm{P}_{\mathrm{v}}[\mathrm{kW}]$ - potrebna snaga $\mathrm{za}$ promenu potencijalne energije helikoptera za datu vertikalnu brzinu ili planirani let.

Empirijski izraz, koji pomaže pri izboru pogonske grupe helikoptera, jeste sledeći:

$$
\mathrm{P}=\dot{0}, 736 \sqrt{\frac{\mathrm{m}^{3} \mathrm{H}}{\mathrm{a}^{2} \mathrm{D}^{2}{ }_{\mathrm{R}}}}[\mathrm{kW}]
$$

gde je:

$\mathrm{m}_{\mathrm{H}}[\mathrm{kg}]$ - ukupna masa helikoptera;

$\mathrm{D}$ [m] - prečnik glavnog rotora;

a

- koeficijent karakteristike nosećeg rotora (vrednost od 15 do 20).

Na slici 1 prikazan je strukturni dijagram preporuke za izbor raspoložive snage gasoturbinskog motora (GTM) i njihovog broja, u zavisnosti od maksimalne mase helikoptera $u$ poletanju. Dijagram se odnosi na buduće savremene koncepcije jednorotornih helikop-

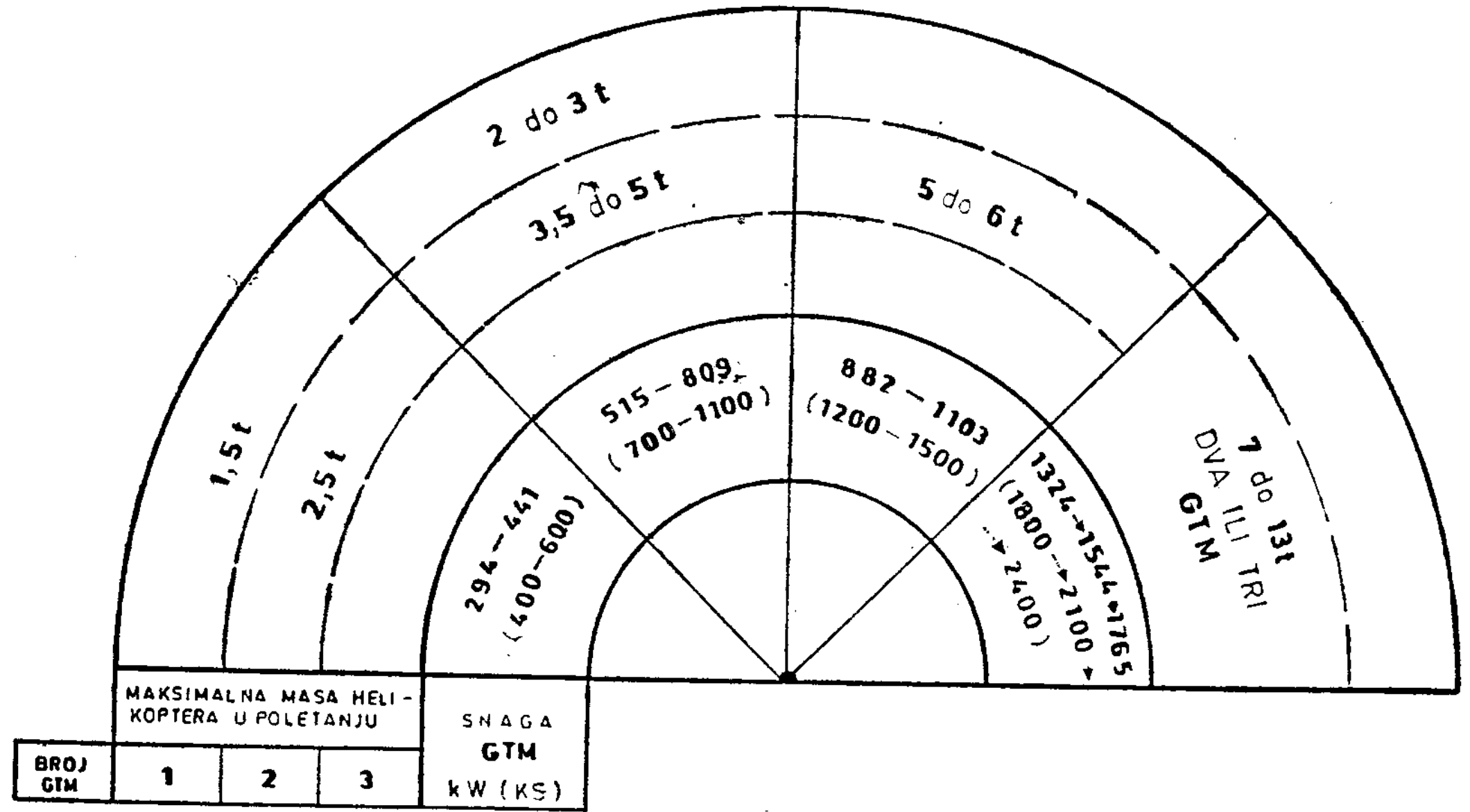

Sl. 1 - Strukturni dijagram preporuke snaga i broja GTM u zavisnosti od maksimalne mase helikoptera $u$ poletanju 
tera. Korišcenje dijagrama je orijentaciono, jer izbor pogonske grupe direktno zavisi od namene i željenih performansi helikoptera u letu.

Zahtevi za sve većom upotrebom helikoptera, kako u vojne, tako i u civilne svrhe, ubrzali su razvoj nove generacije GTM. Osnovni zahtevi koje treba da zadovolje helikopterske gasne turbine, su:

- visok stepen pouzdanosti rada;

- što manja specifična potrošnja goriva $\left(C_{\mathrm{sp}}\right)$ na režimima eksploatacije, uz nisku specifičnu masu $\left(\mathrm{C}_{\mathrm{sm}}\right)$;

- što duži rok rada (resurs);

- pouzdano startovanje i ubrzavanje; lisanje;

- jednostavno upravljanje i regu-

— što niži dozvoljeni nivo vibracija i buke;

- jednostavno i lako održavanje i eksploatacija;

- niska cena, izrade, održavanja i generalne opravke.

Ovi zahtevi su međusobno protivurečni, pa se za određeni tip motora nalaze kompromisna rešenja pri njegovom projektovanju i izradi. Pri tome se ,svakako, polazi od tehničkih zahteva $u$ pogledu optimizacije pogonske grupe sa helikopterom. Kao ilustracija složenosti procesa razvoja i životnog veka GTM prikazan je strukturni dijagram životnog veka GTM (slika 2).

Osnovni pravci daljeg razvoja gasnih turbina su:

- povećanje efikasnosti radnog ciklusa na račun povećanja stepena sabijanja vazduha u kompresoru $\left(\pi_{k}\right)$, temperature izduvnih gasova ispred turbine $\left(\mathrm{T}_{3}\right)$, kao i sniženje gubitaka na osnovnim sklopovima motora;

- primena novih materijala otpornih na visoke temperature i koroziju, kao i lakih materijala za pojedine delove motora;
- usavršavanje konstruktivno-tehnoloških rešenja uz primenu novih tehnologija.

Međusobno preplitanje uticaja specifičnih parametara GTM, njegova konstrukcija, primenjene tehnologije, ugrađeni materijali i sama izrada, zajednički usmeravaju dalji razvoj GTM.

Osnovni pokazatelj kvaliteta konstrukcije i izrade GTM je kvalitet njegovog kompresora. Težnja je da se sa što manje stupnjeva postigne što veći stepen sabijanja $\left(\pi_{k}\right)$ i što veći stepen korisnosti $\left(\eta_{\mathrm{k}}\right)$.

Trend rasta stepena sabijanja kompresora $\left(\pi_{\mathrm{k}}\right)$ kod GTM, za period od 1960. do 2000. prikazan je na slici 3 . $\mathrm{Na}$ slici su, pored oznaka postojećih GTM, označeni i tipovi kompresora sa brojem stupnjeva. Sa slike se vidi da vrednost stepena sabijanja dostiže vrednosti veće od 18.

Ako se uspe u povećanju stepena korisnosti kompresora $\left(\eta_{\mathrm{k}}\right)$ za $2 \%$, uz poboljšanje zaptivanja $i$ hlađenja za $25 \%$, može se očekivati ostvarenje optimalnog ciklusa sa stepenom sabijanja $\pi_{\mathrm{k}}=23$ i temperaturom na ulazu u turbinu $\mathrm{T}_{3}=1.600 \mathrm{~K}$. Time bi se smanjila specifična potrošnja za $8 \%$, a sve navedeno bi se moglo očekivati na GTM do 1995.

Prikaz stalnog rasta temperature ispred turbina $\left(T_{3}\right)$, sa primenom različitih tehnologija izrade i konstruktivne koncepcije GTM, dat je na slici 4 . Sa slike se vidi da će se opseg temperature $\mathrm{T}_{3}$ kretati između 1.600 do 1.700 $\mathrm{K}$.

Ovakav porast temperature postiže se uvođenjem hlađenja lopatica turbine, novom tehnologijom livenja lopatica (monoks istalne), novim materijalima lopatica (superlegure) i uz primenu plazma prevlaka na bazi keramike.

Radi postizanja što veće ekonomičnosti teži se smanjenju specifične potrošnje $\left(C_{\mathrm{sp}}\right)$ goriva. Trend njenog sma- 
Tehnološka razrada materijala i procesa

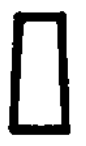

Izbor sklopova i agregata

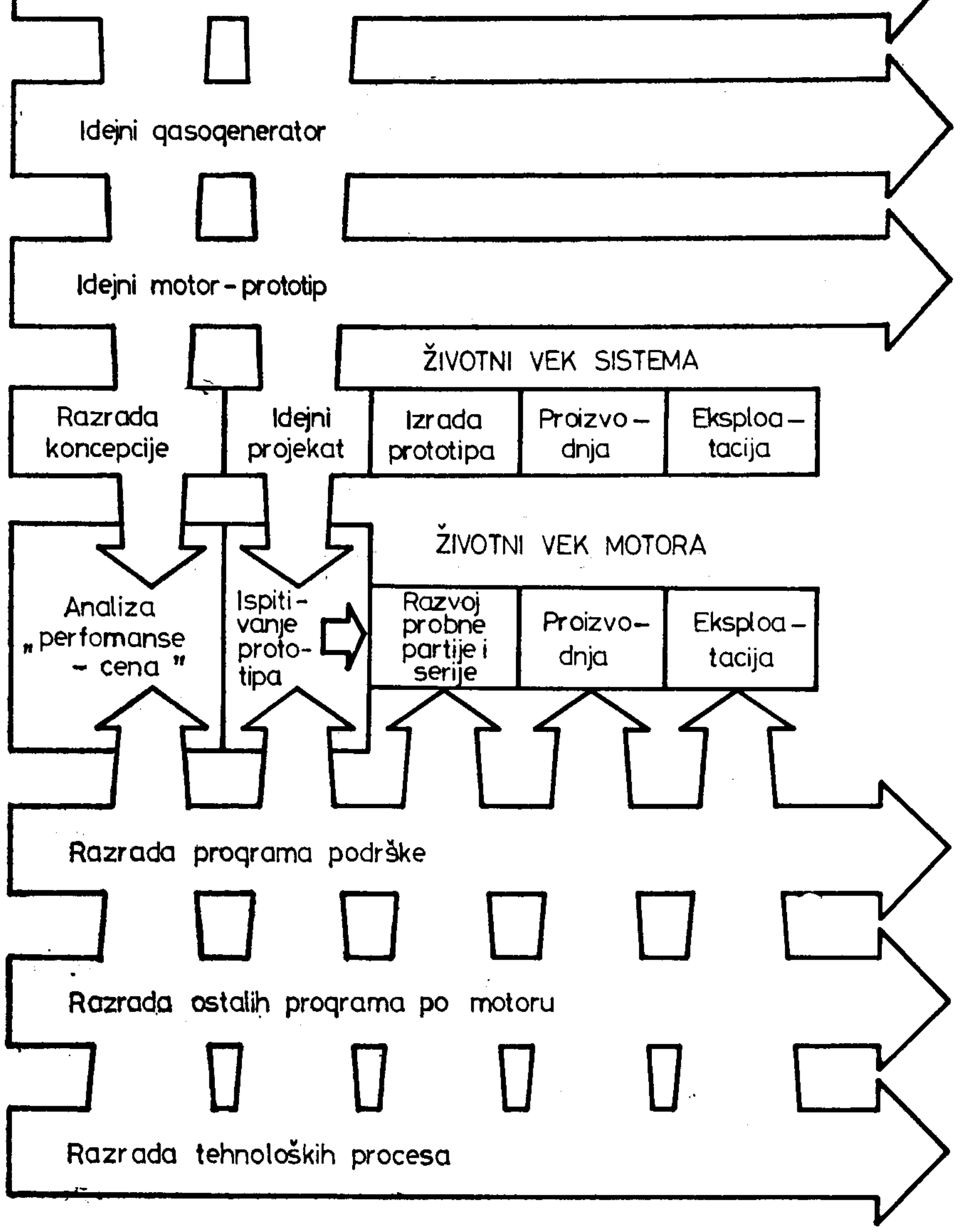

Sl. 2 - Strukturni dijagram životnog veka GTM 


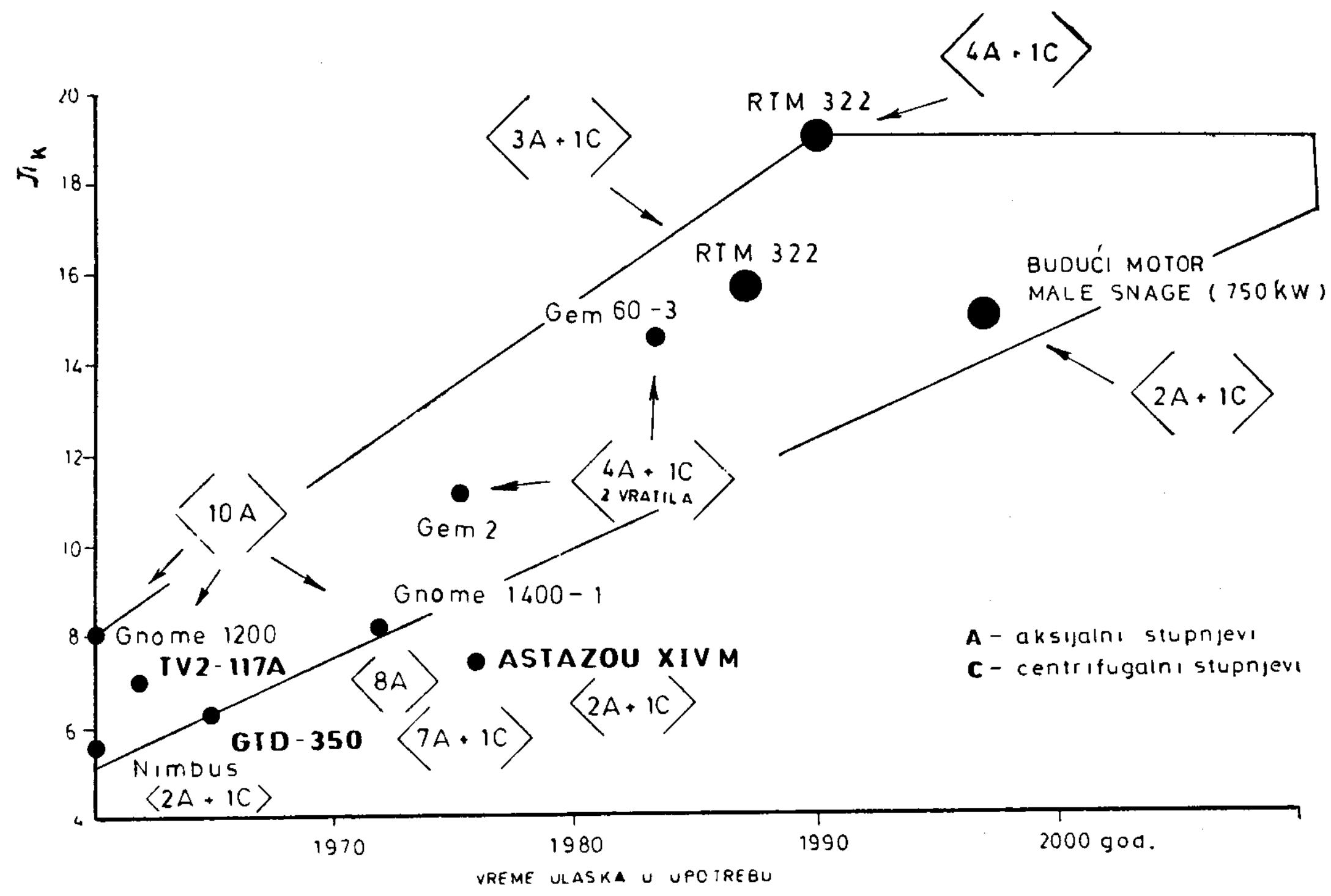

Sl. 3 - Trend rasta stepena sabijanja kompresora $\left(\pi_{k}\right)$ GTM

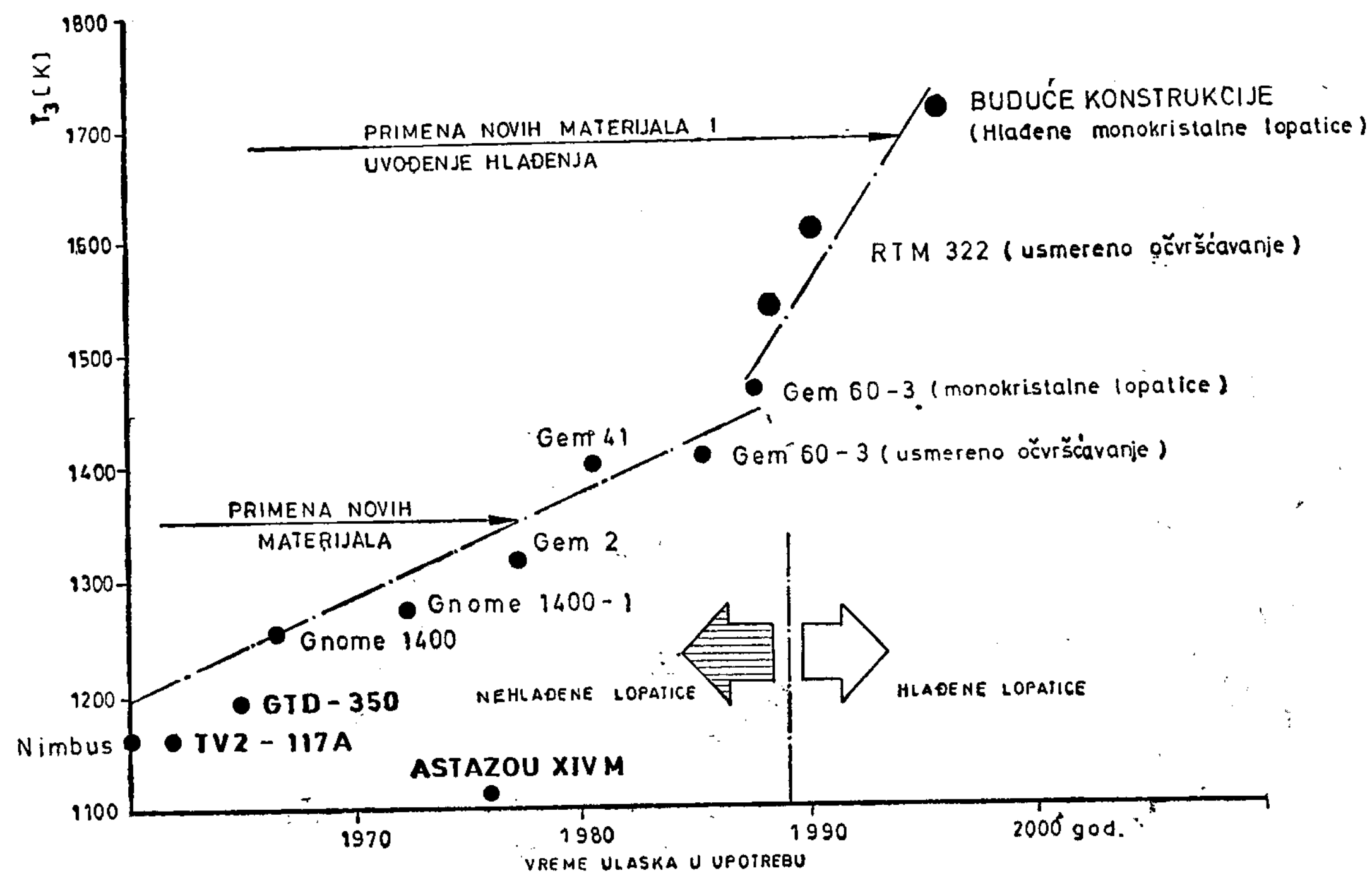

Sl. 4 - Trend rasta temperature ispred turbine $\left(T_{3}\right)$ GTM 
njenja, u zavisnosti od maksimalne snage GTM, prikazan je na slici 5 .

Trend stalnog smanjenja specifične potrošnje goriva u funkciji vremena ulaska motora u upotrebu prikazan je na slici 6.

U narednom periodu očekuje se specifična potrošnja u intervalu od 250 do $280 \mathrm{~g} / \mathrm{kWh}$.

Ovako sniženje je moguće postići, pored navedenog, konstruktivnim poboljšanjem, uvođenjem novih materijala, poboljšanjem zaptivanja, zakretanjem statorskih lopatica kompresora i izborom optimalnog sistema automatskog upravljanja i regulisanja protoka goriva.

Kao pokazatelj ekonomičnosti GTM, pored specifične potrošnje goriva, koristi se i specifična potrošnja ulja, koja treba da bude što niža (ispod $0,5 \mathrm{~kg} / \mathrm{h})$.

Specifična masa $\left(\mathrm{m}_{\mathrm{sp}}\right)$ GTM zavisi od parametara radnog ciklusa $i$ konstrukcije, kvaliteta konstruktivnih materijala i savremene konstruktivne koncepcije motora. Sa manjom specifičnom masom manja je i ukupna masa motora pri zadanoj snazi.

Trend smanjenja specifične mase GTM prikazan je na slici 7. U narednom periodu očekuju se konstrukcije sa specifičnom masom $u$ intervalu od 0,12 do $0,24 \mathrm{~kg} / \mathrm{kW}$.

U pogledu usavršavanja konstrukcije uvode se širokotetivne lopatice kompresora, diskovi rotora od legura titana i zavarivanje snopom elektrona sklopa disk-vratilo kompresora.

Uvođenje novih tehnologija: elektrohemijska obrada, profilno valjanje i precizno kovanje pojeftinjuju izradu složenog aeroprofila rotorskih i statorskih lopatica kompresora, uz ispunjenje zahteva strogih tolerancija. Poseban tehnološki progres predstavlja izrada diskova kompresora HIP (Hot Isostatic Pressing) postupkom (izostatičko presovanje na visokim temperaturama).
Za naredne generacije GTM predviđaju se sledeće konstruktivno-tehnološke karakteristike:

- modularnost (omogućuje brzu zamenu u eksploataciji nekog od modula - sklopa);

- univerzalno konstruktivno izvođenje sklopa kompresor - turbina (»jezgro motora«). Oko omogućuje lak prelazak gasne turbine $u$ varijante turboelisnog i turboventilatorskog GTM (slika 8);

- upotreba grejne komore povratnog dejstva (»obrnute«);

- uvođenje elektronskog sistema regulacije sa digitalnom kontrolom i dijagnostikom;

- uvođenje sistema za merenje obrtnog momenta na induktivnom i optičkom principu;

- povećanje roka rada (resursa) motora na preko 3000 časova;

- smanjenje infracrvenog zračenja radi smanjenja mogućnosti detekcije.

Kao primer pèrspektivnog GTM, u pogledu performansi i konstruktivno-tehnoloških rešenja, može poslužiti motor RTM-322, koji je nastao zajedničkom saradnjom firmi ROLS-ROJS (V. Britanija), i TURBOMEKA (Francuska) (slika 9).

\section{Modifikacije na postojećim konstrukcijama GTM}

Jedna od najznačajnijih osobenosti današnjih konstrukcija helikopterskih GTM predstavlja proizvodnja osnovnog tipa uz više modifikacija, koje se razlikuju po snazi radi različite primene na helikopterima. Ovakav pristup konstrukciji diktiran je ekonomskim faktorima, jer zahteva manje vremena i sredstava nego što je potrebno za nov razvoj konstrukcije. 


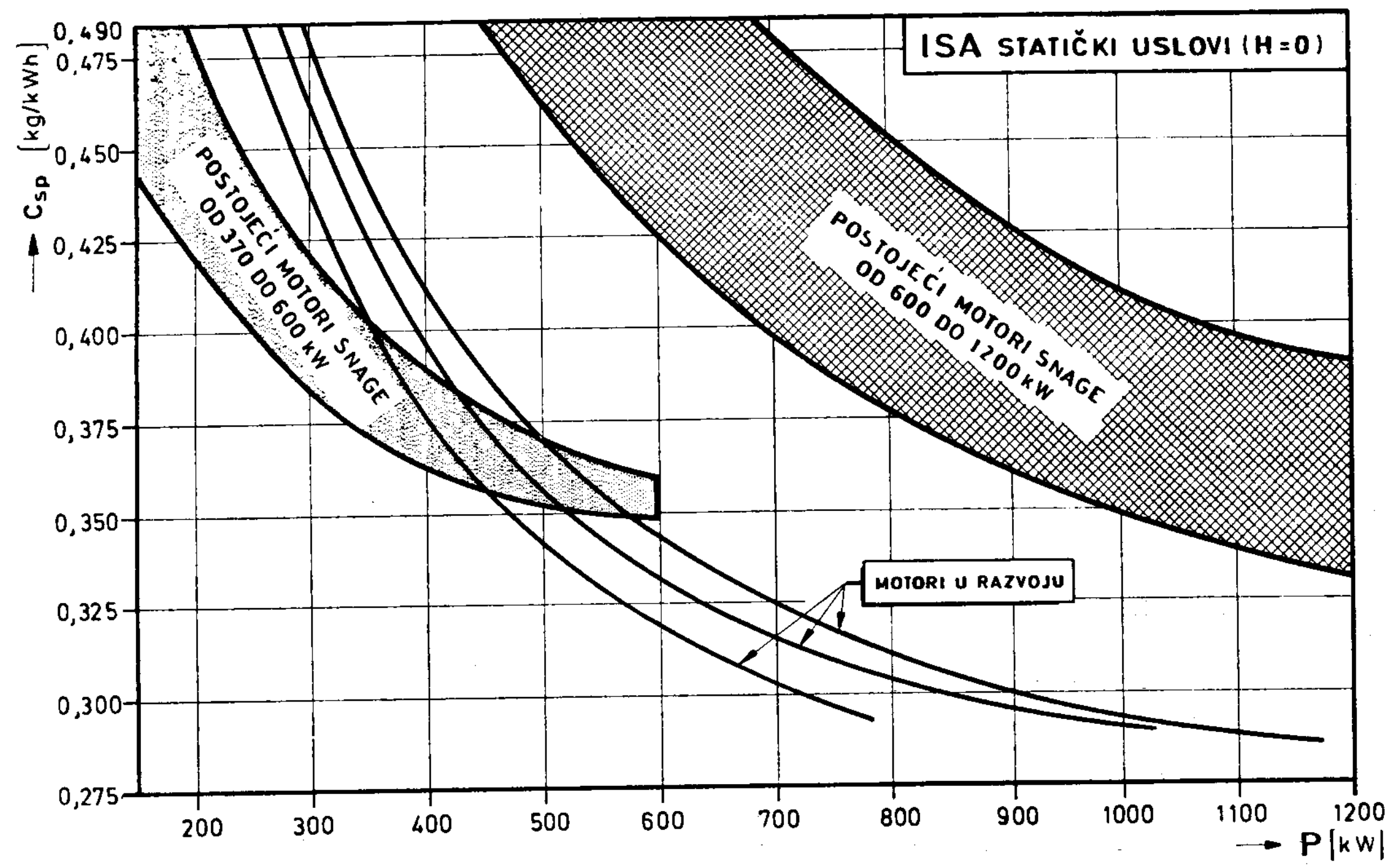

Sl. 5 - Zavisnost specifične potrošnje goriva od snage za helikopterske gasne turbine

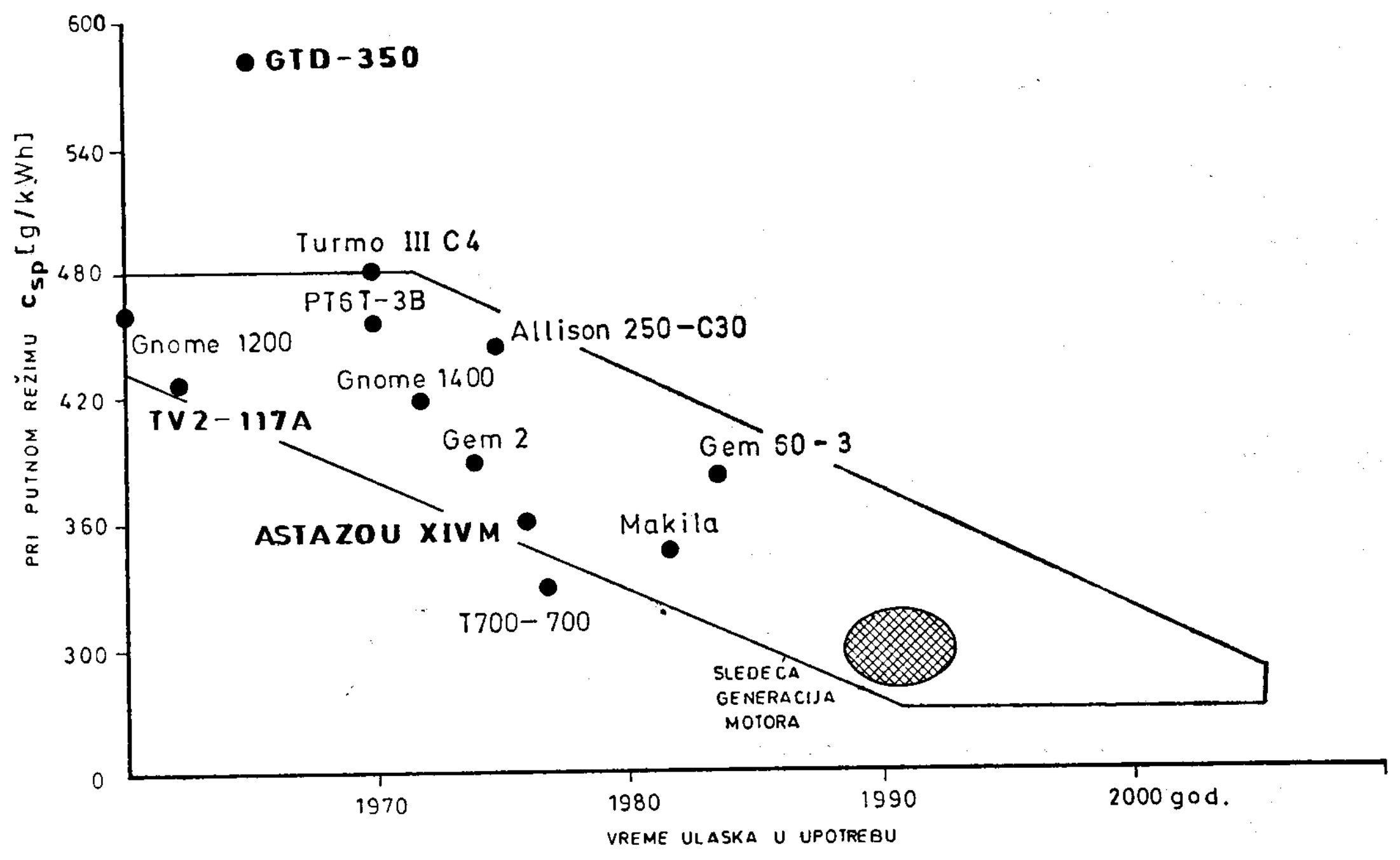

Sl. 6 - Trend smanjenja specifične potrošnje goriva $\left(C_{s p}\right)$ GTM 


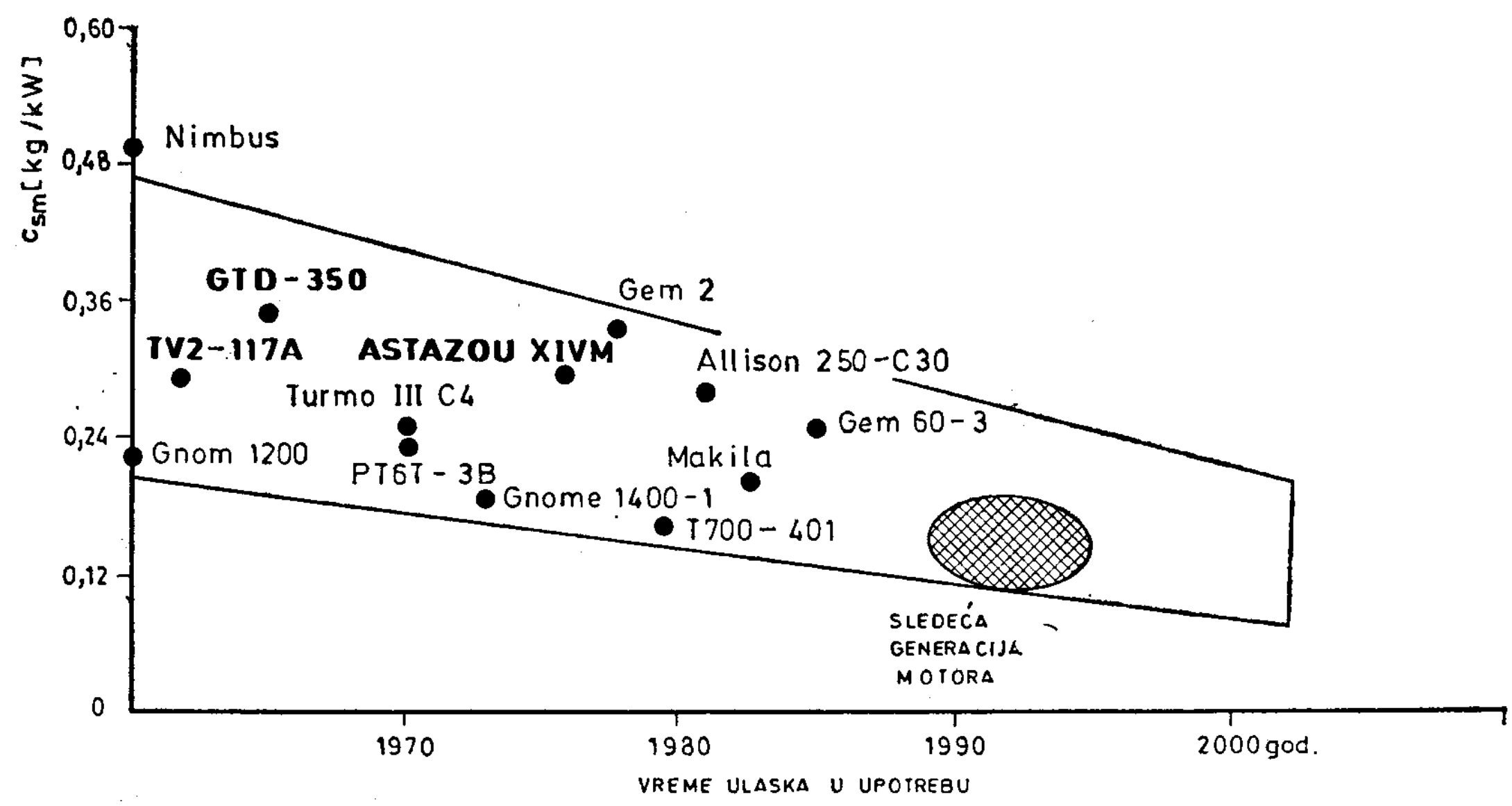

Sl. 7 - Trend smanjenja specifične mase motora $\left(C_{s m}\right)$ GTM

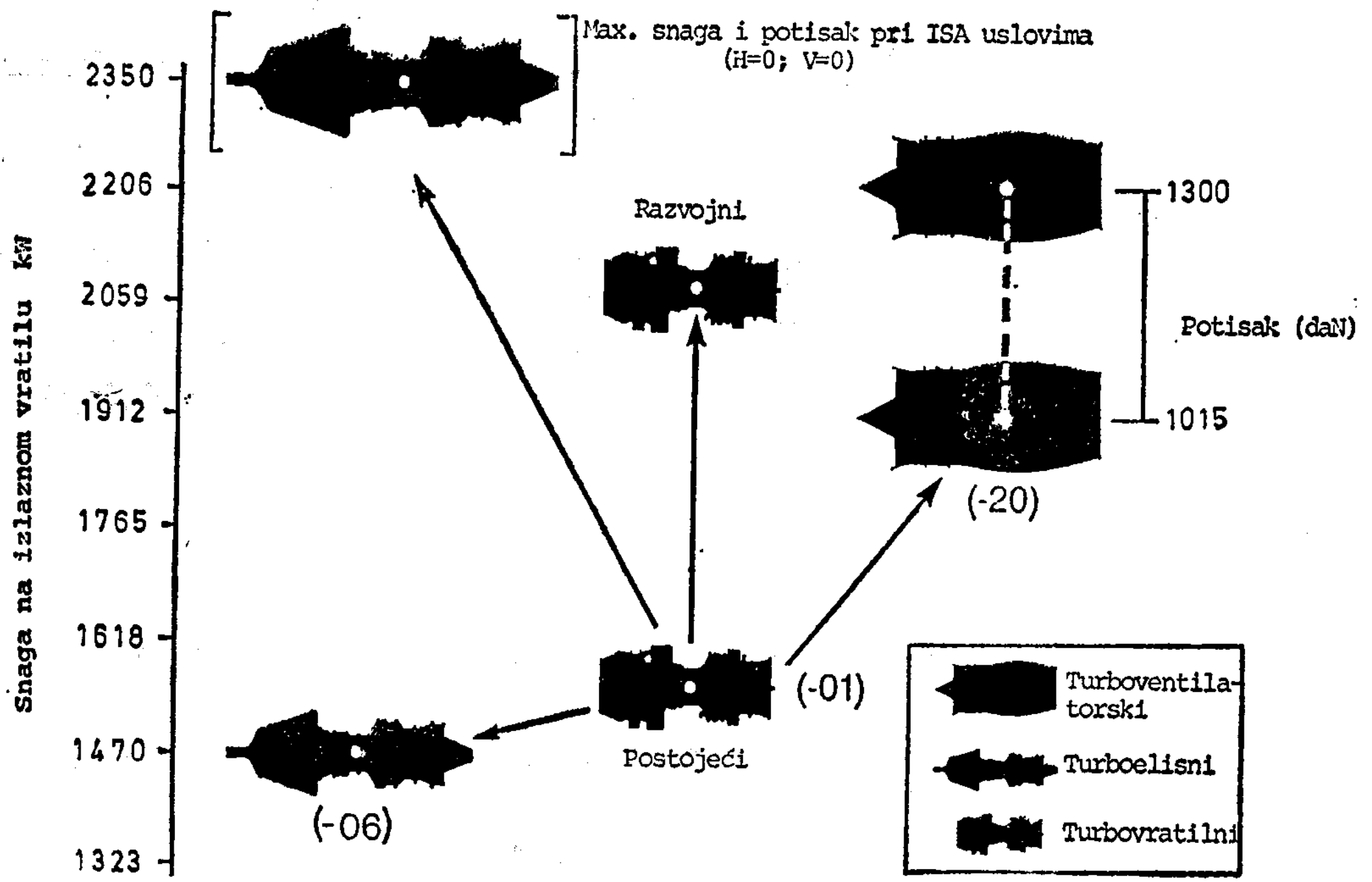

Sl. 8 - Razvojne mogućnosti primene GTM RTM 322 


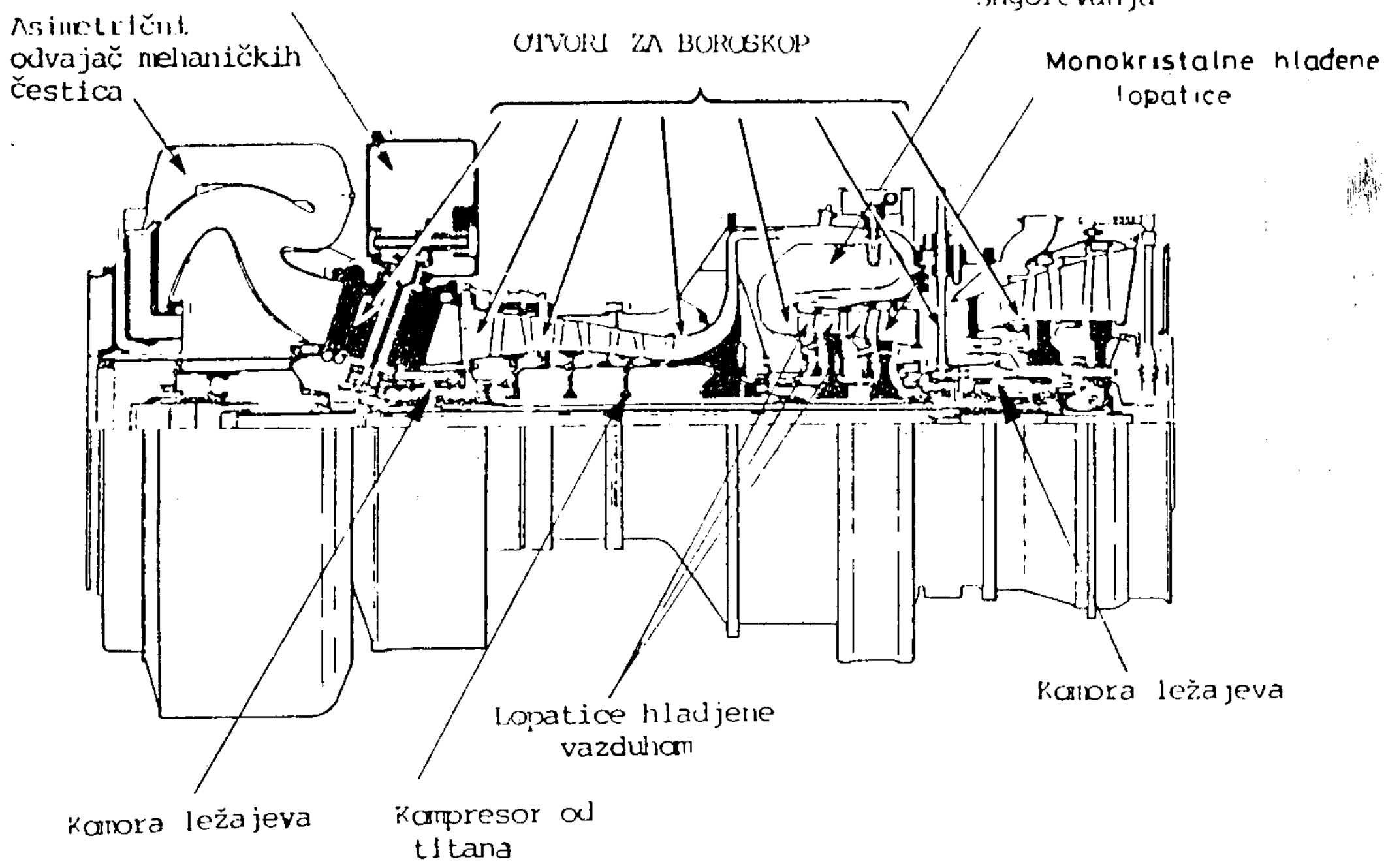

\section{A - KONTROLNI PREGLEDI NA} ZEMLJI

- nivo ulja u rezervoaru, tor,

- pritisak goriva na ulazu u mo-

- prečistač goriva i ulja,

- magnetni detektori opiljaka,

- uzorak ulja za program spektrometrijske analize,

- pregled delova sa boroskopom,

- provera vibracija,

- ispitivanje i kontrola uređaja za
B - STANDARDNI POKAZIVAČI KONTROLE U LETU bine,

- (n)slobodne i kompresorske tur-

- temperatura gasova ispred turbine kompresora $\left(\mathrm{T}_{3}\right)$, bine,

- obrtni moment slobodne tur-

- pritisak ulja iza prečistača,

- temperatura ulja iz hladnjaka. gorivo.

C - DODATNA ISPITIVANJA I KONTROLA RADA NA ZEMLJI I U LETU

- Dodatna oprema sa davačima i pisačem za snimanje i registrovanje parametara rada motora.

Sl. 9 - Delimičan presek sa mestima za kontrolu rada GTM RTM 322 
Zbog zajedničkih delova i sklopova, na različitim tipovima GTM, ekonomski faktor je posebno izražen pri njihovom održavanju.

Ovakav pravac u razvoju GTM u praksi su potvrdile najpoznatije firme u SAD (DŽENERAL ELEKTRIK, LAJKOMING, ALISON, PRAT-VITNI, BOING, KONTINENTAL), Francuskoj (TURBOMEKA), Engleskoj (ROLSROJS), Nemačkoj i državama bivšeg SSSR-a.

Pri tome, za GTM sa visokim specifičnim parametrima, razrada novih modifikacija se vrši radi dobijanja gasoturbinskih motora veće snage, dok se kod GTM sa niskim specifičnim parametrima ide na znatno poboljšanje ekonomičnosti i smanjenje specifične mase, uz istovremeno povećanje snage.

Rezultat ovakvog pristupa je originalna konstrukcija GTM koja ima visoke specifične parametre, iz koje se dalje razvija cela familija GTM.

Uporedo sa specifičnostima svakog proizvođača GTM, u procesu razvoja njegovog modela GTM uočavaju se opšte zakonomernosti. One su sve u funkciji snage GTM, a vezane su za:

- koncepciju konstrukcije GTM (jednovratilni ili sa slobodnom turbinom);

- tip kompresora;

- tip grejne komore;

- postojanje reduktora;

- stepen sabijanja;

- specifičnu potrošnju goriva.

Upoređenje navedenih konstruktivnih podataka, u zavisnosti od snage GTM, prikazano je na slikama 10 i 11 .

I - Analizom podataka sa slike 10 može se zaključiti:

a) Najveći broj modifikacija imaju GTM u opsegu snaga 184 do $551 \mathrm{~kW}$ ( 250 do $750 \mathrm{KS})$ i 735 do $1.470 \mathrm{~kW}(1.000$ do $2.000 \mathrm{KS}$ ), koji se primenjuju na lakim i srednjim helikopterima.

b) Većina konstruktivnih koncepcija GTM ima slobodnu turbinu. Jed- novratilna koncepcija se praktično primenjuje samo do maksimalne snage od $735 \mathrm{~kW}$ (1.000 KS), jer pri manjim snagama ova koncepcija je u prednosti u odnosu na koncepciju sa slobodnom turbinom.

c) Reduktor se primenjuje na svim GTM, snage do $735 \mathrm{~kW}$ (1.000 KS). GTM sa snagama u opsegu od 919 do 1.470 $\mathrm{kW}$ (1.250 do $2.000 \mathrm{KS}$ ) imaju približno podjednak broj modifikacija sa reduktorom i bez reduktora. GTM sa maksimalnim snagama izvode se bez reduktora, zbog nižih brzina obrtanja, dok GTM malih snaga imaju poteškoće $u$ konstrukciji spoja motor - glavni reduktor, zbog visokih brzina obrtanja. To je razlog da se reduktor na ovim tipovima motora konstruktivno izvodi integralno sa GTM.

d) Najčešće primenjivani tipovi kompresora, na helikopterskim GTM, jesu aksijalno-radijalni i radijalni (centrifugalni). Radijalni kompresori imaju ograničenu primenu samo kod GTM malih snaga, do $368 \mathrm{~kW}$ (500 KS).

e) Najčešće se primenjuje grejna komora prstenastog tipa.

f) Grejna komora prstenastog tipa primenjuje se u najvećem broju konstrukcija GTM, od čega trećinu čine prstenaste komore sa povratnim dejstvom. Ovaj tip grejne komore izvodi se radi skraćenja dužine rotora turbokompresora i dobijanja krutosti konstrukcije sa dva oslonca (ležaja).

II - Analizom podataka sa slike 11 može se zaključiti:

a) Stepen sabijanja vazduha u kompresoru $\pi_{\mathrm{k}}$ raste sa povećanjem snage GTM. Povećanjem stepena sabijanja i stepena korisnosti kompresora, uz odgovarajući porast masenog protoka vazduha, postiže se poboljšanje ekonomičnosti GTM, u zavisnosti od porasta snage motora jedne familije.

b) Specifična masa GTM znatno se snižava pri povećanju njegovih dimenzija. To se teoretski tumači time što se pri geometrijskoj sličnosti, smanjenjem 

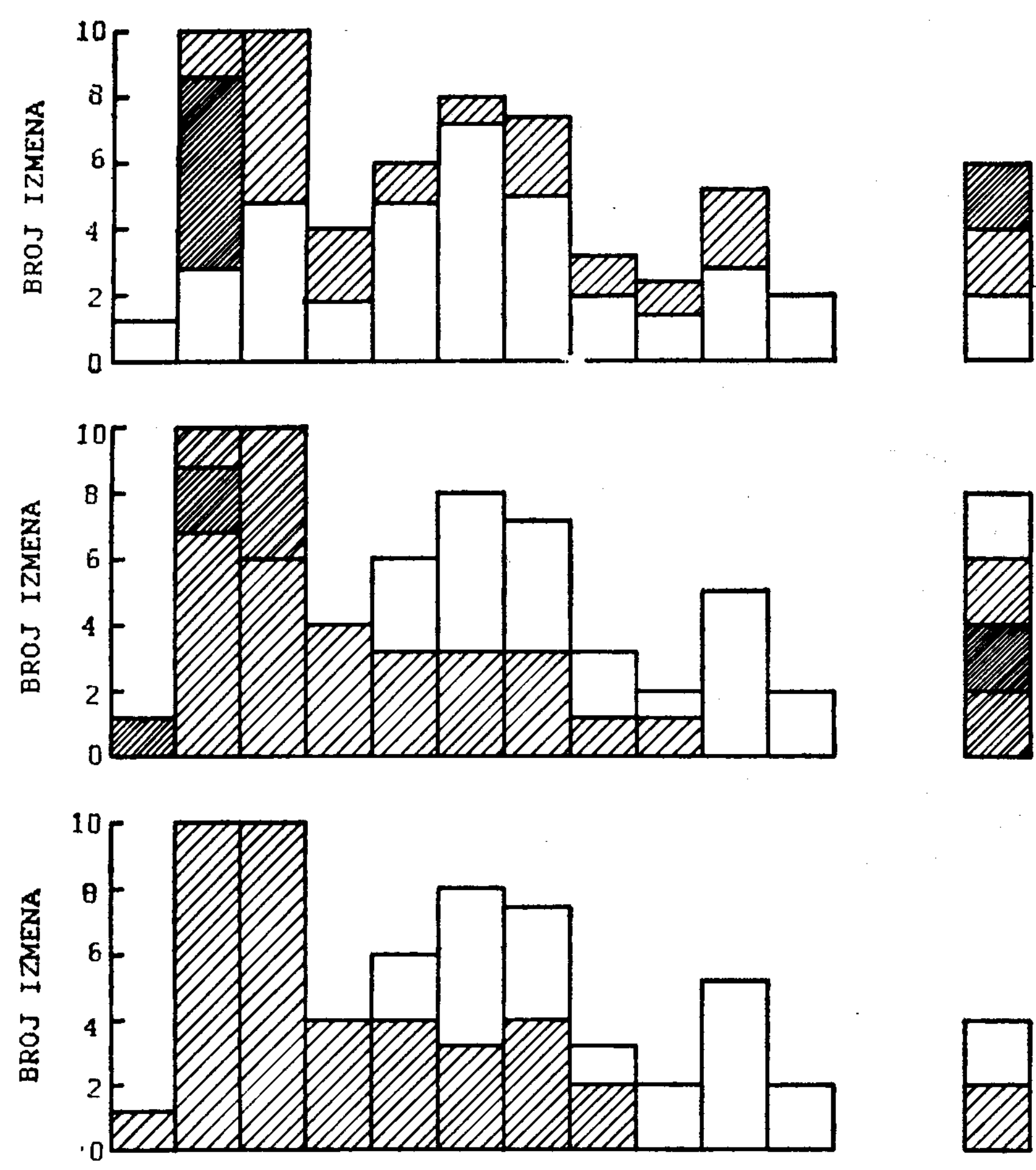

TIP GREJNE ROMORE

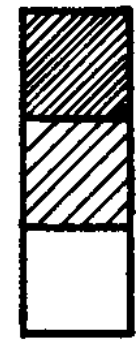

cevasta

prstenasta sa povratim dejstvom

prstenasto
prototna

TIP ROMPRESORA

aksijalni aksijalno

- rajijalni

radijalnz sa

jednim stvorjem

radjjalni sa

dva stupnja

\section{REDURTOR}

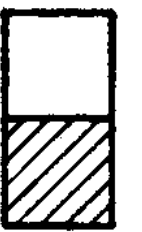

hez radus:ora

sa reduktorom

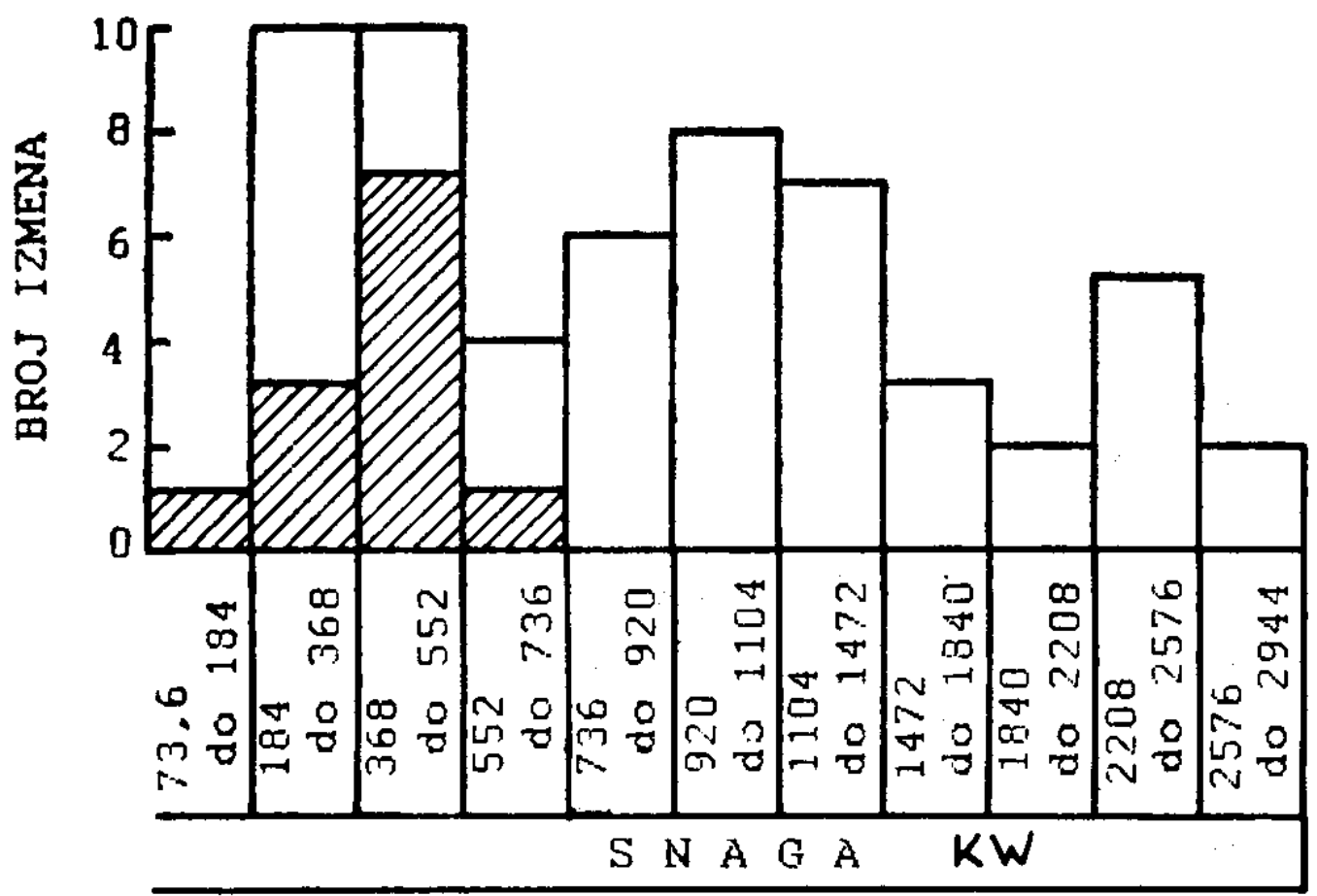

IIP MOTOPA

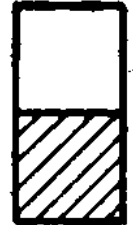

sa siobodnom

turbinom

jednovratilni

Sl. 10 - Konstruktivne karakteristike helikopterskih gasnih turbina u zavisnosti od opsega snaga 

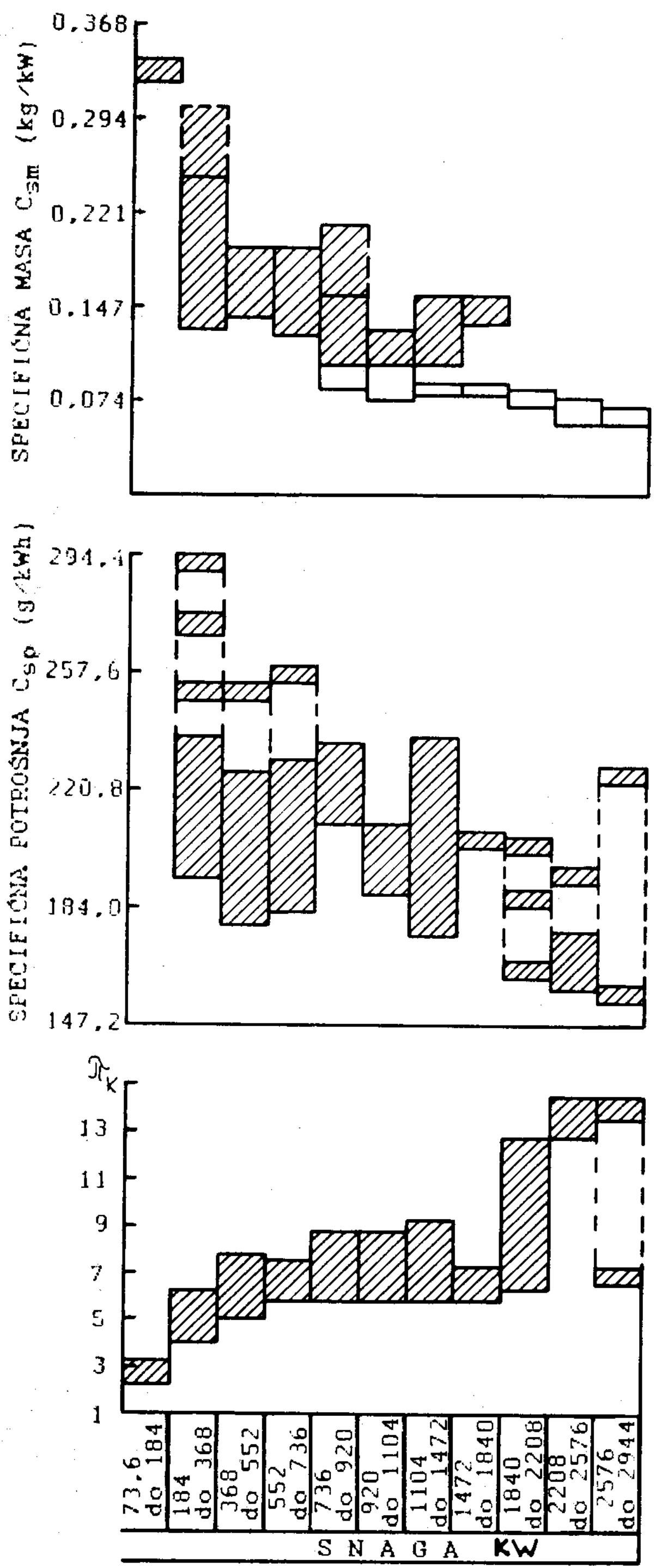

SA REDURTOROM

BEZ REDUKTORA

Sl. 11 - Zavisnost stepena sabijanja $\left(\pi_{k}\right)$, specifične potrošnje $\left(C_{s p}\right)$ i specijalne mase $\left(C_{s m}\right)$, helikopterskih GTM u zavisnosti od opsega snage 
svih dimenzija GTM, uz očuvanje gasodinamičke sličnosti, specifična masa smanjuje sa snižavanjem snage. Pri tome ce se snaga menjati proporcionalno kvadratu linearnih dimenzija, a masa po kubnoj zavisnosti. Međutim, u praksi, smanjenje dimenzija GTM zahteva konstruktivno povećanje relativne debljine delova, zbog tehnoloških zahteva. Istovremeno, masa agregata i oprema po sistemima GTM (gorivo, ulje, vazduh), relativno raste. Pri svemu tome treba naglasiti da se istovremeno smanjuje i specifična snaga GTM, zbog pogoršanja stepena korisnosti toplotnih mašina smanjenih dimenzija. Time se objašnjava i povećanje specifične mase GTM malih snaga.

Korišćenjem reduktora, zbog povećane brzine obrtanja, dolazi do značajnog povećanja specifične mase.

\section{Rezime}

Prema dosadašnjim saznanjima i iskustvu, dalji razvoj GTM biće usmeren na tri osnovna pravca:

- razvoj novih konstruktivnih rešenja, na već postojećim GTM.

Razvoj će biti, prvenstveno, usmeren na povećanje efikasnosti kompresora i turbine, smanjenje specifične potrošnje i mase, poboljšanje performansi, povećanje veka rada (resursa) i pouzdanosti, poboljšanje pogodnosti za održavanje i remont, kao i uvođenje automatske regulacije goriva sa mikroprocesorima;

— razvoj novih materijala.
$\mathrm{Za}$ ispunjenje navedenih konstruktivnih zahteva, neophodno je razviti nove materijale koji moraju da zadovolje oprečne zahteve. Prema sadašnjim saznanjima, ovakve zahteve mogu da obezbede sledeći materijali:

৯ lake legure na bazi aluminijum - litijum;

- legure titana;

- superlegure na bazi nikla i kobalta;

A kompozitni materijali;

A materijali na bazi keramike;

— razvoj novih tehnologija.

Za razvoj novih materijala i njihovu obradu neophodne su nove tehnologije, kao što su:

\ precizno livenje i kovanje;

\ zavarivanje elektronskim snopom;

A indukciono zavarivanje;

- elektrohemijska obraada;

- toplo izostatičko presovanje;

- livenje lopatica turbine sa usmerenom kristalizacijom i monokristalom;

- nove zaštitne prevlake otporne na koroziju, toplotu i habanje.

Kroz dosadašnji razvoj licenci GTM u zemlji osvojena je većina navedenih tehnologija, što predstavlja kvalitetnu osnovu za dalja usavršavanja i eventualni domaći razvoj.

[5] Publikacije firmi: TURBOMECA, ROLLS-ROYCE, GENERAL ELECRTIC, SNECMA, PR \& WHITNEY, AEROSPATIALE, SIKORSKY, WESTLAND, BOEING I AVCO LYCOMING.

[6] Dr S. Janković: Modeliranje univerzalne ispitne stanice $z a$ pouzdano i ekonomično ispitivanje helikopterskih gasnih turbina, Doktorska disertacija, 1991. 